\title{
Clinical course of cirrhosis in young adults and therapeutic potential of liver transplantation
}

\author{
J J KEATING, R D JOHNSON, P J JOHNSON, AND ROGER WILLIAMS \\ From the Liver Unit, King's College Hospital and School of Medicine and Dentistry, Denmark Hill, London
}

SUMMARY The lack of information on survival in young adults with cirrhosis and the increasing use of liver transplantation in this age group have led us to carry out a retrospective analysis of the clinical course and survival in 83 young adults aged between 15 and 30 years presenting to the Liver Unit between 1970 and 1983 . Fifty four $(65 \%)$ patients had cirrhosis at initial presentation and in the remaining $29(35 \%)$ this developed within the study period. The overall five year survival of the group, excluding 14 cases treated by transplantation, was $70 \%$. When considered according to aetiological groups this was $83 \%$ in those with chronic active hepatitis, $60 \%$ in those with cryptogenic cirrhosis and $37 \%$ in Wilson's disease. When considered in relation to Child's grading, only three deaths occurred in the 45 patients with well-compensated liver disease (Child's grade A and B). Of the 38 patients with Child's grade C, 20 (83\%) of the 24 patients not undergoing transplantation have died, whereas eight $(57 \%)$ of the 14 receiving liver grafts are alive and well.

Cirrhosis of the liver is predominantly a disease of late middle and old age, and in three large European studies less than $5 \%$ of cases occurred under the age of 30 years. ${ }^{1-3}$ Little information is available on presentation or survival in this younger age group. This is particularly relevant now that improved results are being obtained with liver transplantation. ${ }^{4}$ When considering patients for liver transplantation in the Cambridge/King's College Hospital programme, we attempt to choose a stage in disease progression where survival is likely to be less than one year and the patient is greatly incapacitated but not too sick to withstand the trauma of the procedure and the difficult postoperative period.

In this report we describe the clinical course of a series of 83 young adults with cirrhosis presenting over a 13 year period with particular respect to survival, disease severity, and grade. Some of the Child's grade $C$ patients were treated by transplantation and survival in this group was compared with those with comparable clinical state who were treated conservatively.

Address for correspondence: Dr Roger Williams, FRCP, Liver Unit, King's College Hospital, Denmark Hill, London SE5 9RS

Received for publication 8 February 1985

\section{Methods}

PATIENTS

Between 1970 and 1983, 83 British born young adults with chronic liver disease were referred to the Liver Unit. In $54(65 \%)$ patients cirrhosis was already established at the time of presentation and in the remaining $29(35 \%)$ this developed within the study period and before reaching the age of 30 years. The largest aetiological group comprised 39 patients (10 men) with HBsAg seronegative chronic active hepatitis (CAH). The other groups included cryptogenic cirrhosis, 16 (six men); Wilson's disease, nine (five men); HBsAg sero-positive $\mathrm{CAH}$, eight (seven men); alcoholic cirrhosis, four (four men); primary sclerosing cholangitis, four (three men); and cirrhosis from $\alpha_{1}$-antitrypsin deficiency, three (one man).

The sera of 28 patients $(71 \%)$ with HBsAg seronegative $\mathrm{CAH}$ contained autoantibodies (antinuclear and/or smooth muscle) in titres of at least $1: 40$ while raised $(>15 \mathrm{~g} / \mathrm{l})$ serum immunoglobulin $\mathrm{G}$ was present in $32(82 \%)$ of these patients. Patients labelled as having 'cryptogenic cirrhosis' had no clinical or histological evidence of known aetiological factor or detectable autoantibodies.

Histological confirmation of cirrhosis was 
obtained in 80 patients - in 69 by percutaneous liver biopsy during life, six at necropsy and in five during liver transplantation. In the remaining three patients who are still alive coagulation defects prevented a liver biopsy, and cirrhosis was diagnosed on the basis of cutaneous clinical signs, isotope scan appearances and the presence of oesophageal varices.

ASSESSMENT OF SEVERITY OF LIVER DISEASE Pugh's modification of the Child's classification was used. ${ }^{5}$ Those patients whose score totalled 5 or 6 were classified as Child's grade $A ; 7,8$, or 9 as Child's grade B; and patients with 10-15 Child's grade $C$ (Table 1 ). The grade $A$ and $B$ cases were considered to have well compensated liver disease.

Grading was documented at the time when first seen in the Liver Unit and serially during the follow up period. All patients with Child's grade $\mathrm{C}$ disease were assessed for transplantation, as described elsewhere, by ultrasound and coeliac angiography to assess the patency of the portal vein. ${ }^{6}$

\section{STATISTICAL ANALYSIS}

Survival was calculated by life table analysis and survival times were (right) censored for all patients who had not died at the time of analysis. ${ }^{7}$ Statistical significance of differences between the groups was assessed by the log rank test. ${ }^{8}$

\section{Results}

At the time of presentation jaundice and constitutional symptoms were present in $82 \%$ of those with chronic active hepatitis (CAH) but only $31 \%$ with cryptogenic cirrhosis, in which haematemesis was the main event leading to presentation. This occurred in $69 \%$ of the patients with cryptogenic cirrhosis compared with $23 \%$ in the chronic active hepatitis group (Table 2). At presentation 50 patients had
Table 1 Grading of severity of liver disease

\begin{tabular}{|c|c|c|c|}
\hline \multirow{2}{*}{$\begin{array}{l}\text { Clinical and biochemical } \\
\text { measurements }\end{array}$} & \multicolumn{3}{|c|}{$\begin{array}{l}\text { Points scored for increasing } \\
\text { abnormality }\end{array}$} \\
\hline & 1 & 2 & 3 \\
\hline Encephalopathy (grade)* & None & 1 and 2 & 3 and 4 \\
\hline Ascites & Absent & Slight & Moderate \\
\hline Bilirubin $(\mu \mathrm{mol} / \mathrm{l})$ & $<40$ & $40-60$ & $>60$ \\
\hline Albumin (g/l) & $>3 \cdot 5$ & $2 \cdot 8-3 \cdot 5$ & $<2 \cdot 8$ \\
\hline $\begin{array}{l}\text { Prothrombin time } \\
\text { (secs prolonged) }\end{array}$ & $1-4$ & $4-6$ & $>6$ \\
\hline
\end{tabular}

* according to grading of Trey, Burns, and Saunders (1966)

well compensated liver disease, and 33 were in Child's grade C (17 chronic active hepatitis, seven cryptogenic cirrhosis, nine Wilson's disease). Thirty nine patients with HBsAg seronegative chronic active hepatitis received a maintenance treatment of prednisolone $5-20 \mathrm{mg} /$ day and 23 patients received azathioprine $75-100 \mathrm{mg} /$ day in addition. Twenty two (47\%) chronic active hepatitis patients who had no histological features of cirrhosis at presentation went on to develop cirrhosis during the study period while receiving continuous steroid medication.

The overall five year survival of the group, excluding the 14 cases treated by transplantation, was $70 \%$ from presentation (Fig. 1), and $52 \%$ from the time of developing cirrhosis. When considered according to aetiological groups, five year survival was $83 \%$ in those with chronic active hepatitis and $60 \%$ in those with cryptogenic cirrhosis (Fig. 1). The highest mortality rate was in patients with Wilson's disease (37\% alive at five years) (Fig. 1), where symptoms had been present for longer than six months. These patients presented with jaundice, abdominal pain, and ascites and received 1-2 $g$ of d-penicillamine daily after diagnosis. Only three patients responded to this treatment, while in the

Table 2 Clinical findings in the 83 patients at the time of presentation to King's College Hospital

\begin{tabular}{|c|c|c|c|c|c|c|c|}
\hline & \multicolumn{2}{|l|}{$C A H$} & \multirow[b]{2}{*}{$\begin{array}{l}\text { Cryptogenic } \\
16 \text { cases }\end{array}$} & \multirow[b]{2}{*}{$\begin{array}{l}\text { Wilsons } \\
9 \text { cases }\end{array}$} & \multicolumn{2}{|l|}{ Others } & \multirow[b]{2}{*}{$\begin{array}{l}\text { Total } \\
83 \text { cases }\end{array}$} \\
\hline & $\begin{array}{l}\text { Cirrhotic } \\
25 \text { cases }\end{array}$ & $\begin{array}{l}\text { Precirrhotic } \\
22 \text { cases }\end{array}$ & & & $\begin{array}{l}\text { Cirrhotic } \\
4 \text { cases }\end{array}$ & $\begin{array}{l}\text { Precirrhotic } \\
7 \text { cases }\end{array}$ & \\
\hline Haematemesis & 8 & 3 & 11 & 1 & 2 & 0 & 25 \\
\hline Jaundice & 14 & 9 & 3 & 5 & 4 & 6 & 41 \\
\hline Encephalopathy & 3 & 0 & 2 & 0 & 0 & 0 & 5 \\
\hline Abdominal pain & 3 & 1 & 2 & 7 & 3 & 0 & 16 \\
\hline Malaise, anorexia & 2 & 8 & 0 & 1 & 2 & 3 & 16 \\
\hline Arthalgia & 0 & 2 & 0 & 0 & 0 & 0 & 2 \\
\hline Hepatomegaly & 10 & 7 & 6 & 7 & 3 & 5 & 38 \\
\hline Splenomegaly & 19 & 13 & 13 & 9 & 4 & 2 & 60 \\
\hline Ascites & 22 & 3 & 5 & 7 & 1 & 0 & 38 \\
\hline
\end{tabular}




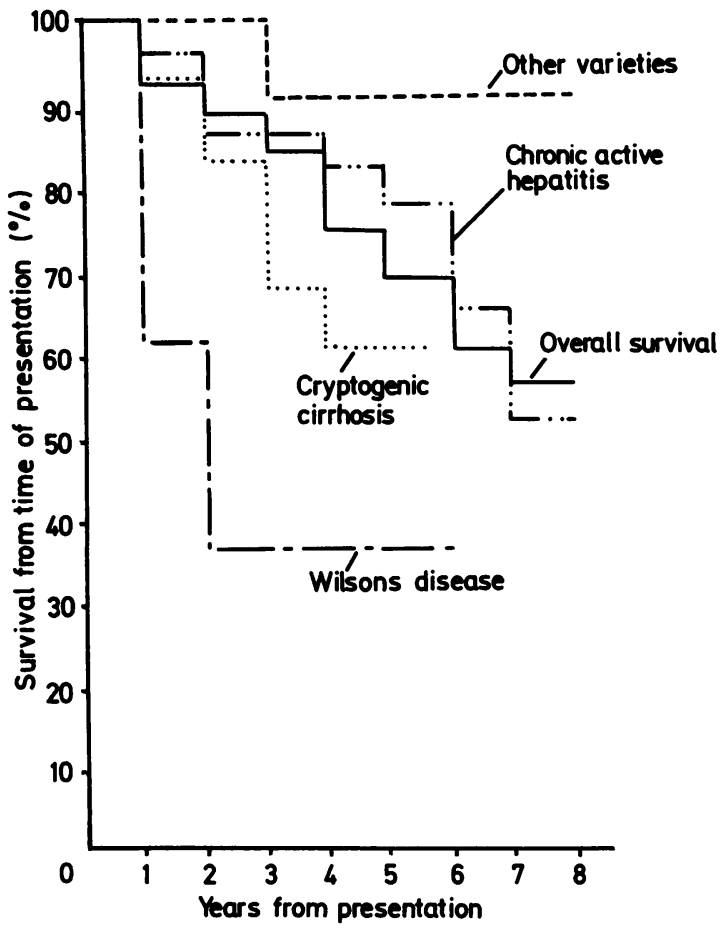

Fig. 1 Comparison of survival in the various aetiological groups excluding those transplanted.

remaining six decompensated liver disease persisted.

Mortality was almost entirely confined to patients with Child's grade $\mathrm{C}$ liver disease. Thus only three of 45 patients with well-compensated cirrhosis (Child's A and B) have died - one of a traumatic ruptured spleen, one consequent on the development of a hepatocellular carcinoma, both in chronic active hepatitis patients, and a third patient died of a cholangiocarcinoma as a complication of sclerosing cholangitis. In contrast, 20 of $24(83 \%)$ in the
Child's C group treated conservatively have died, the commonest immediate cause of death being sepsis with underlying hepatocellular failure and/or renal failure (Table 3).

\section{USE OF LIVER TRANSPLANTATION}

Thirty eight patients with grade $\mathrm{C}$ liver disease were considered for transplantation. Analysis of individual clinical features showed the presence of deep jaundice in $23(60 \%)$, diuretic resistant ascited in 30 $79 \%$ ), episodes of encephalopathy in $12(31 \%)$ and recurrent episodes of bleeding varices in $22(58 \%)$.

Transplantation was finally undertaken in 14 of these-patients (nine chronic active hepatitis, four cryptogenic cirrhosis, one Wilson's disease). Eight patients were excluded because of the finding of a portal vein block on ultrasound examination or angiography, and of the remaining 16 patients eight decided against the procedure, four died before a donor became available and four had deteriorated to a stage where transplantation could no longer be considered. The mean delay between initial assessment and transplantation was six weeks \pm four weeks. At the time of assessment for transplantation the Child's score of those not undergoing surgery (mean score 11) was not significantly different from those transplanted (mean score 12). Comparison of survival in the two groups by life table analysis (log rank test) showed that the transplanted group survived significantly longer $(65 \%$ at one year compared with $35 \%, \mathrm{p}<0.05$ ) (Fig. 2). Only six $(42 \%)$ of the transplanted group have died compared with $83 \%$ of the conservatively treated group. Four of these deaths occurred within four months of surgery because of a combination of poor graft function, renal failure, and sepsis. The other two died of chronic rejection, one at six months and the other at two years, both before cyclosporin became available. Of the eight surviving patients (six with chronic active hepatitis, one with cryptogenic cirrhosis, one with Wilson's disease), seven are well and have returned to work. The two patients are alive at

Table 3 Causes of death in the 69 patients treated conservatively

\begin{tabular}{|c|c|c|c|c|c|}
\hline & $C A H(38)$ & Cryptogenic (12) & Wilson's (8) & Others (11) & Total 69 \\
\hline Total number of deaths & 12 & 5 & 5 & 1 & 23 \\
\hline $\begin{array}{l}\text { Sepsis with underlying hepatic failure } \\
\text { and/or renal failure }\end{array}$ & 7 & 5 & 4 & - & 16 \\
\hline Haematemesis & $\begin{array}{l}3 \\
*(1 \text { ruptured spleen })\end{array}$ & - & 1 & - & 4 \\
\hline Hepatocellular carcinoma & $\begin{array}{l}2 \\
*(1 \text { Child's A })\end{array}$ & - & - & - & 2 \\
\hline Cholangiocarcinoma & - & - & - & ${ }^{*}(1$ Child's A) & 1 \\
\hline
\end{tabular}

* Deaths occurring in Child's Grade A 


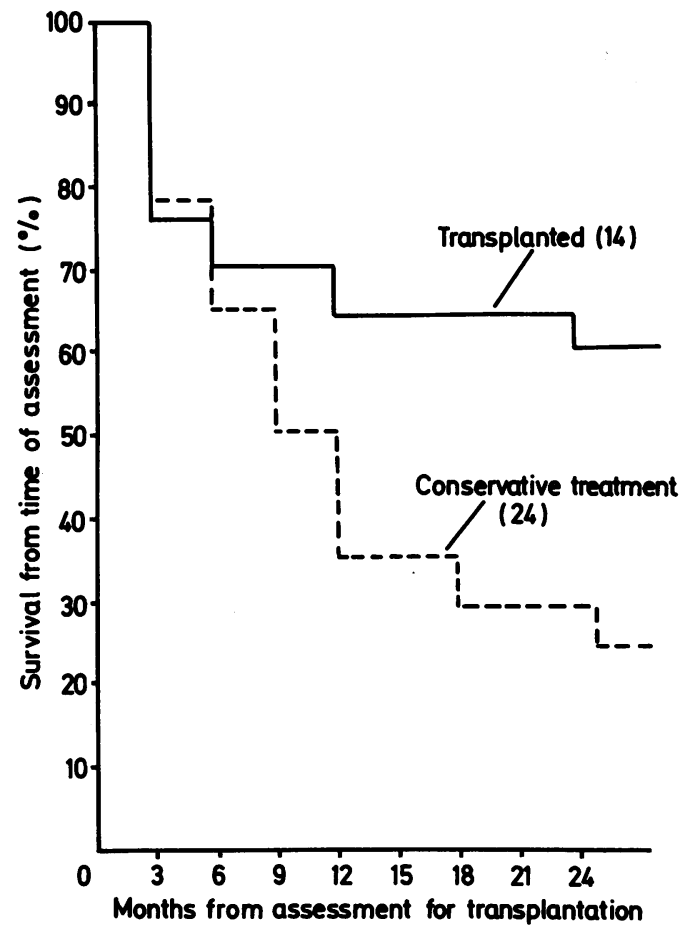

Fig. 2 Comparison of survival in Child's grade $C$ patients treated conservatively and in those undergoing transplantation.

four years, two at three years and two at two years as measured from the time of assessment for transplantation.

\section{Discussion}

There are a number of reasons for the better overall five year survival rates in young cirrhotics in this series than that reported in predominantly older age groups. In the Birmingham series where the five year survival rate was $30 \%$, the mean age of presentation was 55 years with only $3 \%$ being under the age of 30 years. Over $50 \%$ had alcoholic cirrhosis, with only $5 \%$ having chronic active hepatitis, ${ }^{2}$ compared with $5 \%$ with alcoholic cirrhosis and $56 \%$ with chronic active hepatitis in the present series. Although alcoholic cirrhosis may have a good prognosis if the patient becomes abstinent, this was the case in only $19 \%$ of the patients in the Birmingham series. Younger patients with chronic active hepatitis have a better prognosis as they can be treated with corticosteroids.

Survival figures from the Royal Free Hospital, ${ }^{9}$ the Mayo Clinic, ${ }^{10}$ and from this series are all quite similar $-80 \%, 93 \%$, and $83 \%$ respectively of the chronic active hepatitis patients treated with corticosteroids are alive five years after presentation. The groups are not strictly comparable, however, as we studied only $\mathrm{CAH}$ cirrhotic patients, whereas only approximately $40 \%$ of the patients in the other two series were cirrhotic. The development of cirrhosis in $47 \%$ of the chronic active hepatitis patients while receiving corticosteroid therapy suggests that this treatment may not prevent progression of disease. The Mayo Clinic series has shown, in addition, that it is this cirrhotic subgroup who are invariably associated with relapse if treatment is withdrawn. ${ }^{11}$

The poor survival of the Wilson's disease patients (37\% alive at five years) despite exclusion of those with fulminant hepatic failure, probably reflects the fact that all our patients were decompensated at presentation. In a recent series from the Royal Free Hospital survival was also poor $(47 \%$ alive at five years) among 17 Wilson's patients with chronic active hepatitis, 15 of whom had cirrhosis at presentation. ${ }^{12}$ Only $37 \%$ of our Wilson's disease patients had a sustained improvement in biochemistry and hepatic histology; in the remainder a relentless downhill course ensued. Our experience is in accord with Sternlieb who considered that failure of a two to three month course of chelation therapy in patients with decompensated Wilson's cirrhosis is an indication for liver transplantation. ${ }^{13}$

In this study mortality was closely related to hepatic decompensation. Eighty three per cent of the Child's grade $\mathrm{C}$ group not transplanted have died, compared with only $6 \%$ of the well compensated Child's A and B group ( $4 \%$ as a consequence of primary liver tumour development).

In considering results of transplantation in the decompensated (Child's C) patients, although the cases were not randomly allocated the two groups did appear to be well matched with no statistical difference in their Child's scores of disease severity. Transplantation appeared to reduce mortality significantly, the one year survival being $65 \%$ in the transplanted group and only $35 \%$ in those receiving standard medical treatment. The quality of life also differed between the two groups, those not undergoing transplantation having predominantly a hospital dependent life suffering recurrent bouts of encephalopathy, septicaemia, peritonitis and variceal haemorrhage and finally dying of these complications.

\section{References}

1 Stone WD, Islam NRK, Paton A. The natural history of cirrhosis: experience with an unselected group of 
patients. $Q J$ Med 1968; 37: 119-32.

2 Saunders JB, Walters JRF, Davies P, Paton A. A 20 year prospective study of cirrhosis. $\mathrm{Br}$ Med J 1981; 282: 263-6.

3 Hallen J, Linne I. Cirrhosis of the liver in one community. In: Engel E, Larson T, eds. Alcoholic cirrhosis and other toxic hepatopathies. Stockholm: Nordiska Bokhandelrs Forlag, 1970: 336-55.

4 Williams R, Calne RY, Rolles K, Polson RJ. Current results with orthotopic liver grafting in the Cambridge/ King's College Hospital series. Br Med J 1985; 290: 49-52.

5 Pugh RNH, Murray-Lyon IM, Dawson JL. Transection of the oesophagus for bleeding oesophageal varices. $\mathrm{Br}$ j Surg 1973; 60: 646-9.

6 Calne RY, ed. Liver transplantation. London: Grune and Stratton, 1981: 67-76.

7 Gore SM, Altman DG, eds. Statistics in practice. London: BMA, 1982: 82-5.

8 Peto R, Pike MC, Armitage P, et al. Design and analysis of randomised clinical trial requiring prolonged observations of each patient. II Analysis and example. Br J Cancer 1977; 35: 1-39.

9 Kirk AP, Jain S, Pocock S et al. Late results of the Royal Free Hospital prospective controlled trial of prednisolone therapy in hepatitis B surface antigen negative chronic active hepatitis. Gut 1980; 21: 78-83.

10 Czaja AJ, Wolf AM, Summerskill WHJ. Development and early prognosis of oesophageal varices in severe chronic active liver disease (CALD) treated with prednisolone. Gastroenterology 1979; 77: 627-33.

11 Czaja AJ, Davis GL, Ludwig J, Taswell HF, et al. Complete resolution of inflammatory activity following corticosteroid treatment of $\mathrm{HBsAg}$ negative chronic active hepatitis. Hepatology 1984; 4: 622-7.

12 Scott J, Collan JL, Samourian S, et al. Wilson's disease presenting as chronic active hepatitis. Gastroenterology 1978; 74: 645-51.

13 Sternlieb I. Wilson's disease: indication for liver transplants. Hepatology 1984; 4: 15S-17S. 